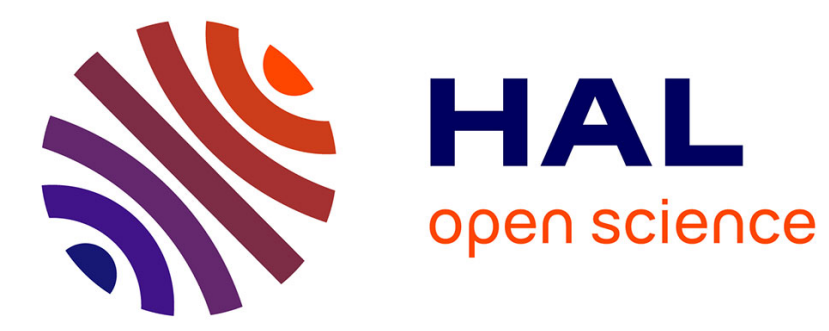

\title{
Poster Abstract: Robust Controlled Invariance for UFAD Regulation
}

Pierre-Jean Meyer, Hosein Nazarpour, Antoine Girard, Emmanuel Witrant

\section{To cite this version:}

Pierre-Jean Meyer, Hosein Nazarpour, Antoine Girard, Emmanuel Witrant. Poster Abstract: Robust Controlled Invariance for UFAD Regulation. BuildSys 2013 - 5th ACM Workshop on Embedded Systems For Energy Efficient Buildings, Nov 2013, Rome, Italy. pp.1 - 2, 10.1145/2528282.2528316 . hal-01492943

\section{HAL Id: hal-01492943 \\ https://hal.science/hal-01492943}

Submitted on 23 Mar 2017

HAL is a multi-disciplinary open access archive for the deposit and dissemination of scientific research documents, whether they are published or not. The documents may come from teaching and research institutions in France or abroad, or from public or private research centers.
L'archive ouverte pluridisciplinaire HAL, est destinée au dépôt et à la diffusion de documents scientifiques de niveau recherche, publiés ou non, émanant des établissements d'enseignement et de recherche français ou étrangers, des laboratoires publics ou privés. 


\section{Poster Abstract: \\ Robust Controlled Invariance for UFAD Regulation}

\author{
Pierre-Jean Meyer \\ LJK \& GIPSA-lab \\ University of Grenoble, France \\ Pierre-Jean.Meyer@imag.fr \\ Antoine Girard \\ LJK \\ University of Grenoble, France \\ Antoine.Girard@imag.fr
}

\author{
Hosein Nazarpour \\ LJK \\ University of Grenoble, France \\ nazarpur@gmail.com \\ Emmanuel Witrant \\ GIPSA-lab \\ University of Grenoble, France \\ Emmanuel.Witrant@gipsa-lab.fr
}

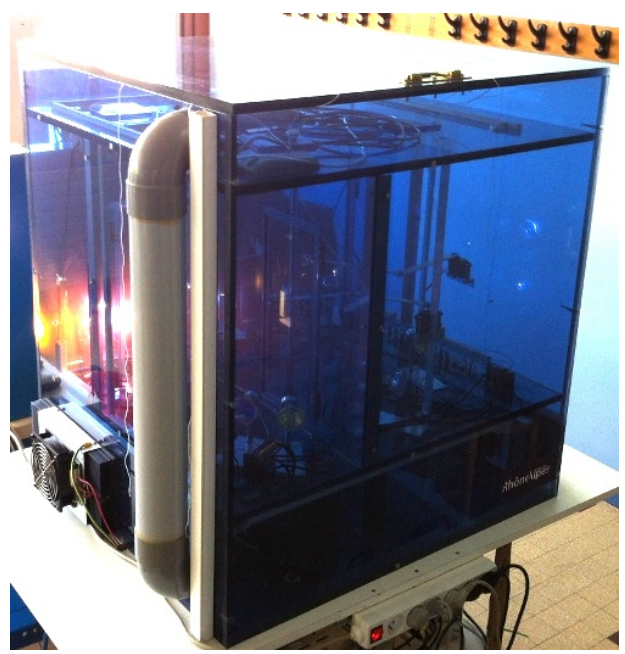

Figure 1: Small-scale experiment of a flat with UFAD regulation

the controlled fans. The excess of air is pushed into the ceiling plenum through exhausts in the fake ceiling and then sent back to the underfloor through a return pipe outside of the flat. Here, the controls at the building level (recirculation, underfloor temperature) are assumed to be set and our focus is on achieving separate climate regulation using decentralized control.

A 0-dimensional model is built based on energy and mass conservation in each room volume. The variation of temperature thus depends on conduction with adjacent rooms, radiation of heat sources and incoming air flow from the underfloor plenum and open doors. See $[2,3]$ for a detailed description on establishing this model.

This work is focused on a small-scale experiment of a 4room flat with UFAD regulation ${ }^{1}$. To identify the theoretical model to the experiment, we run several tests aiming to quantify the heat transfers due to heat radiation, conduction in the walls and the exchange of air flows. The control of the experiment (fans, doors and lamps for the heat sources) and the measurements are done using LabVIEW ${ }^{\mathrm{TM}}$. The data

\footnotetext{
${ }^{1}$ Built at the physics department (UFR PhITEM) of University Joseph Fourier, Grenoble, France.
} 

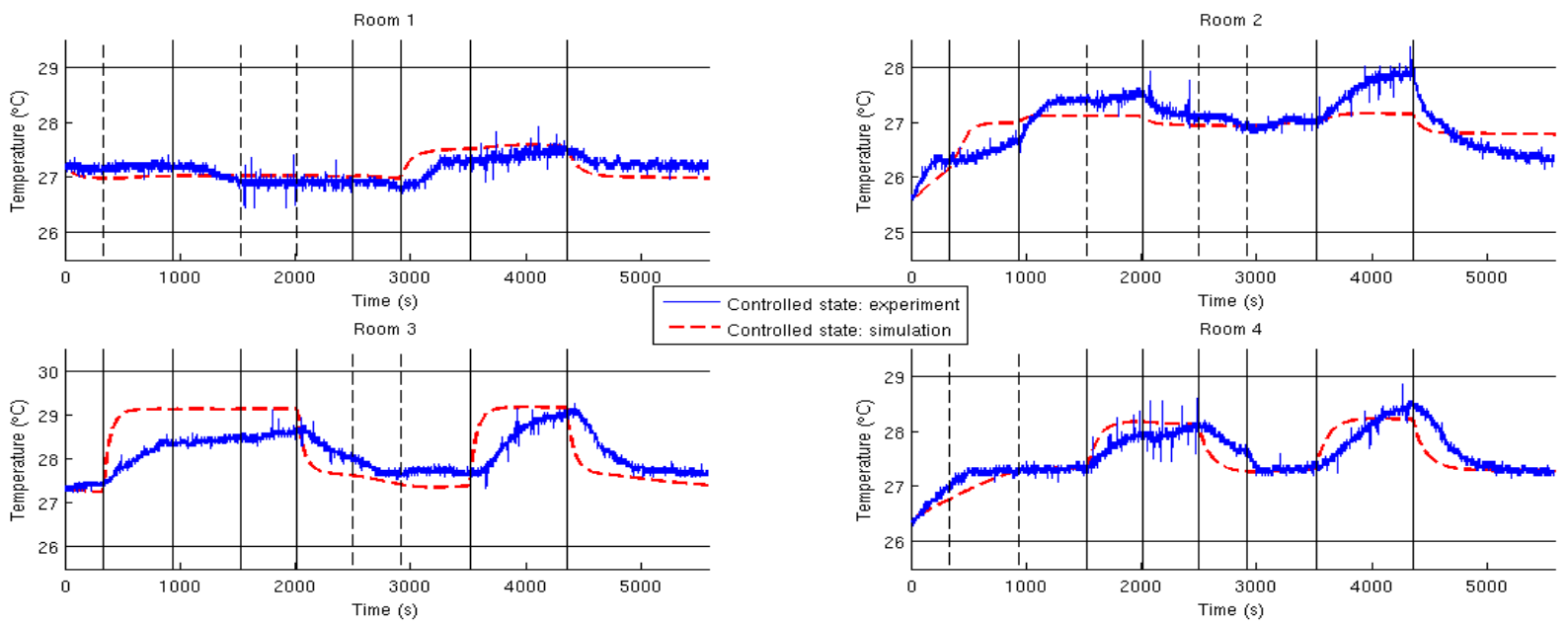

Figure 2: Controlled state, using a saturated linear controller, for the experiment (blue, noisy) and the simulation (red, dashed), with the transitions (vertical lines: solid when linked to the room, dashed otherwise)

are then processed in MATLAB ${ }^{\circledR}$. Our identification problem has 40 unknown parameters, with 10 for each room: 5 for the conduction (underfloor, ceiling, outside, and 2 neighbor rooms), 1 for the fan, 1 for each door, and 2 for the heat source (emissivity and temperature). We solve this optimization problem with a recursive least-squares algorithm initialized with a set of values based on known physical parameters and observations.

The obtained model is then evaluated on experimental scenarios not used in the identification process and covering most of the combinations between the state of the fans and the disturbances. The comparison with the data measured in these scenarios can be used to identify the limitation of our model.

\section{ROBUST CONTROLLED INVARIANCE}

The results we obtained on Robust Controlled Invariance only require the system to verify the monotonicity property [1]. The cooperative systems, a subclass of the monotone systems but with a very similar definition, take their names from an interpretation which gives a clearer understanding of how such systems behave. A system is called cooperative because its variables reinforce each other, or more generally, each pair of variables may affect each other in either positive or negative way. This behavior is quite intuitive for thermal systems: if the neighbor rooms are hotter or there are more heat sources, the considered room will see its temperature increase faster. Similarly, with a low underfloor temperature, increasing the fan air flow would decrease the room temperature faster. The main advantage resulting from the monotonicity of the system is that in what follows we can focus only on the extremal values of each variable.

The main notion developed here is the Robust Controlled Invariance, defined as the ability to maintain the state of the system in a given interval for any value of the disturbances using the control input. From that broad definition and assuming that all inputs are bounded, the monotonicity simplifies this notion by only using the extremal values of the inputs: the worst disturbances with the best associated control to counteract the disturbances. This new characterization, in term of inequalities on the $n$-dimensional vector field, defines two subspaces in which the boundaries of an interval have to be chosen to ensure the Robust Controlled Invariance of this interval. These results thus give the theoretical limits for a robust controller to keep the state in an interval. For a theoretical exposition of these notions, the reader is referred to $[2]^{2}$.

Using the previously identified model, we compute the limits for the Robust Controlled Invariance applied to the small-scale flat and we choose a control interval within these limits. Then we apply a saturated linear strategy to control the underfloor fans. Figure 2 gives the controlled experiment (blue, noisy) and simulation (red, dashed) for a particular switching scenario of the doors and heat sources, where the horizontal lines represent the limits of the control interval.

\section{CONCLUSION}

The main results on Robust Controlled Invariance only require the monotonicity of the system and bounded disturbances which we believe are reasonable assumptions on temperature dynamics in buildings. It provides a generic approach which is independent from the feedback control strategy used and thus leaves a large degree of freedom for the performance specification.

\section{REFERENCES}

[1] D. Angeli and E. D. Sontag. Monotone control systems. IEEE Transactions on Automatic Control, 48(10):1684-1698, 2003.

[2] P.-J. Meyer, A. Girard, and E. Witrant. Controllability and invariance of monotone systems for robust ventilation automation in buildings. In Proceedings of the Conference on Decision and Control, 2013.

[3] E. Witrant, P. Di Marco, P. Park, and C. Briat. Limitations and performances of robust control over WSN: UFAD control in intelligent buildings. IMA Journal of Mathematical Control and Information, 27(4):527-543, 2010.

${ }^{2}$ This paper is available in an extended version at http://hal.archives-ouvertes.fr/docs/00/85/87/15/ PDF/Controllability.pdf 